\title{
СИНТАКСИЧЕСКИЙ ПАРАЛЛЕЛИЗМ КАК СРЕДСТВО КОГЕЗИИ И СПОСОБ СОЗДАНИЯ «НУЖНОЙ» АВТОРУ ТЕКСТОВ ДЕТЕКТИВНОГО ЖАНРА КОГЕРЕНТНОСТИ
}

\section{SYNTACTIC PARALLELISM AS A MEANS OF COHESION AND A WAY TO CREATE A "NECESSARY" COHERENCE FOR AN AUTHOR OF DETECTIVE GENRE TEXTS}

A. Sokolova

Summary: The article is devoted to determining the role and functions of using syntactic parallelism as a means of creating a correct cohesion and necessary coherence for an author of detective genre texts based on the examples from the works of A.C. Doyle. The author of the article notes an important role of syntactic parallelism as a means of motivating authors of detective genre texts to its more frequent and correct use, and recipients of such texts - to complex deduction, development of imagination, and triggering more powerful cognitive processes, which can potentially occur in the consciousness of an individual.

Keywords: cohesion, coherence, syntactic parallelism, stylistics, detective genre, text.

\author{
Соколова Алевтина Владимировна \\ Аспирант, Московский государственный областной \\ университет (2. Мытищи) \\ alevtina-sokolova@rambler.ru
}

Аннотация: Статья посвящена определению роли и функций использования синтаксического параллелизма как средства создания корректной когезии и необходимой автору текстов детективного жанра когерентности на примерах из произведений А.К. Дойла. Автор статьи отмечает важную роль синтаксического параллелизма как средства мотивации авторов детективного жанра к его более частому и правильному использованию, а реципиентов текстов писателей - к сложной дедукции, развитию воображения и к запуску более мощных когнитивных процессов мышления индивидуума, которые могут потенциально происходить в его сознании.

Ключевые слова: когезия, когерентность, синтаксический параллелизм, стилистика, детективный жанр, текст.

преступления), неправильной последовательности изложения в нем событий или наличием слишком прямых намеков на финал произведения, ведь когерентность это еще и «семантико-прагматические (тематические и функциональные в том числе) аспекты смысловой и деятельностной (интерактивной) связности дискурса, как локальной, так и глобальной» [4, с. 195]. Такая ситуация недопустима, поэтому авторы произведений должны использовать различные приемы с целью соблюдения в тексте верной когезии и «нужной» им когерентности. В этой связи, в произведениях именно детективного жанра большую и значимую роль могут играть применяемые писателями синтаксические параллельные конструкции, помогающие авторам произведений выстроить свои тексты правильно не только грамматически, но и семантически, стилистически, а главное, логически.

Для достижения цели нашего исследования - определения видов, функций и важности использования синтаксического параллелизма в создании автором художественного текста детективного жанра правильной когезии и нужной ему когерентности (на материале произведений А. К. Дойла "The Hound of the Baskervilles", "The Valley of Fear", "The Noble Bachelor", "The Gloria Scott"), нам было необходимо решить следующие задачи:

1. рассмотреть понятие синтаксического параллелизма; 
2. выделить и проанализировать выбранные из текстов синтаксически параллельные конструкции;

3. рассмотреть влияние правильно использованных синтаксических параллельных конструкций в произведениях авторов детективного жанра (когезия) на создание правильной и нужной автору когерентности этих текстов (то есть нужного вектора восприятия детективного художественного текста его реципиентами).

Прежде чем непосредственно приступить к анализу конструкций, относящихся к синтаксическому параллелизму и выбранных нами методом сплошной выборки из отрывков текстов произведений А.К. Дойла, считаем необходимым кратко остановиться на основных терминах, которые будут активно использоваться в работе при анализе предложений с синтаксическим параллелизмом.

Начнем с определения понятия «текст». Данному термину посвящено большое количество работ как отечественных (советских и российских), так и зарубежных лингвистов. Однако до сих пор нет единого, наиболее точного и емкого определения этому понятию, что связано, прежде всего, с его сложной природой (лексической, грамматической, смысловой) не только в лингвистике, но и в смежных с ней науках (психолингвистике, нейролингвистике, лингвистике текста и т.д.).

Согласно определениям И.Р. Гальперина [1, с. 18], Н.К. Яшиной [9, с. 10], М.А.К. Халлидея и Р. Хасан [12, с. 1] и др., текст, по их общему мнению, представляет собой некую связную структуру, а создание любого связного текста (в том числе и детективного жанра) - процесс непростой и трудоемкий, но при этом невероятно важный, поскольку даже самое небольшое отсутствие должного перехода в тексте от одной синтаксической единицы к другой может привести (чаще всего и приводит) к частичному, а то и к полному нарушению смысла, который автор вкладывает в этот текст.

Одними из главных составляющих текста являются категории связности и цельности. Проанализировав работы советских (И.Р. Гальперин, Ю.М. Лотман, В.А. Лукин, 3.Я. Тураева), российских (Н.С. Валгина, М.Л. Макаров, Т.В. Милевская, Н.К. Яшина) и зарубежных (R.-A. de Beaugrande и W. Dressler, S.A. Crossley и D.S. McNamara,
T. van Dijk, T. Givon, M.A.K. Halliday и R. Hasan, A. Karadeniz) авторов, мы сделали вывод, что, как и к определению понятия «текст», так и к одним из его главных характеристик - «связности» и «цельности», у ученых также нет единого подхода.

В лингвистке термин cohesion ('когезия') был введен в употребление М.А.К. Халлидеем и Р. Хасан, которые не разграничивали понятия «когезия» и «когерентность», поэтому последние в переводе выступают как «когезия» (от 'cohesion').

В отечественной лингвистике термин определяли И.Р. Гальперин [1, с. 74], В.А. Лукин', Н.С. Валгина², в зарубежной - С.А. Кроссли и Д. МакНамара [10, с. 354], А. Карадениз [13, с. 94] (уже различая эти два понятия).

Среди лингвистов существуют расхождения в понимании сущности и функций двух обсуждаемых и важных характеристик текста - когезии и когерентности, обеспечивающих целостность и единство любого принципиально возможного текста.

А.А. Леонтьев пишет о том, что признаки связности могут относиться к различным классам, и именно к синтаксическим признакам вполне логично относится синтаксический параллелизм³.

О. Донтчева-Навратилова и ряд других авторов утверждают, что одним из средств когезии, а именно структурной когезии является параллелизм [11, с. 11]. То есть связный текст можно создать, используя схожие структуры, расположенные параллельно [11, с. 14].

Для определения (выделения) принципов нахождения параллелизма при анализе отрывков из художественных текстов детективного жанра был проанализирован ряд научных и лексикографических источников: «Словарь лингвистических терминов» О.С. Ахмановой4; «Словарь лингвистических терминов» Т.В. Жеребило5; «Синтаксические конструкции английской разговорной речи» Э.А. Трофимовой [8]; словарь "TKT Glossary of English Language Teaching"б; словарь "Routledge Dictionary of Language and Linguistics" , а также статья "Linguistic Features of Parallelism"8.

В рамках данной статьи возьмем за основу опреде-

Лукин В.А. Художественный текст: Основы лингвистической теории и элементы анализа: Учеб. для филол. спец. вузов. М.: Издательство «Ось-89», 1999. С. 22.

2 Валгина Н.С. Теория текста. М.: Логос, 2003. С. 29.

3 Леонтьев А.А. Основы психолингвистики. 4-е изд., испр. М.: Асademia: Смысл, 2005. С. 90.

4 Ахманова О.С. Словарь лингвистических терминов. 5-е изд. М.: Либроком: URSS, 2009. 569 с.

5 Жеребило Т.В. Словарь лингвистических терминов. Изд. 5-е, испр. и доп. Назрань: ООО «Пилигрим», 2010.486 с.

6 TKT Glossary of English Language Teaching (ELT) Terminology [Электронный ресурс] // Cambridge English: [сайт]. [2015]. URL: https://www.cambridgeenglish.org/Images/22184-tkt-glossary-document.pdf (дата обращения: 01.08.2020).

7 Bussmann H. Routledge Dictionary of Language and Linguistics. London; New York: Routledge, 1996. 1304 p.

8 Linguistic Features of Parallelism [Электронный ресурс] // Iraqi Academic Scientific Journals. Journal of Human Sciences. Babylon University: [сайт]. 2019. vol. 1, no. 26, pp. 1-23. URL: https://iasj.net/iasj?func=article\&ald=159893 (дата обращения: 15.03.2021). 
ление параллелизма из словаря О.С. Ахмановой: «Параллелизм (симметрия) - это связь между отдельными образами, мотивами и т.п. в произведении речи, выражающаяся в одинаковом расположении сходных элементов;одинаковое расположение сходных членов предложения в двух или нескольких смежных предложениях» 9 .

Напомним, что в результате анализа ряда научных работ, посвященных явлению параллелизма (см. [6, 7]), нами было выявлено, что существует несколько его видов, при этом классификации этого явления у разных авторов различаются.

Приведем, в качестве примера, классификацию И.А. Логвиненко, В которой, с нашей точки зрения, представлен наиболее полный список видов параллелизма. Согласно мнению ученого, параллелизм может быть: графическим, звуковым, лексическим, грамматическим (синтаксическим и морфологическим); а также полным и неполным; одночленным, двучленным, многочленным (или сложным); утвердительным и отрицательным; прямым, хиастическим и лестничным; внутристрочным, в смежных строках, внутристрофным; основанным на метафоре, сравнении, метонимии; основанным на синонимии и антонимии ${ }^{10}$.

К. Ришика добавляет к представленной классификации еще и конструкционный параллелизм, выделенный Р.О. Якобсоном, и внутритекстовый параллелизм [7, с. 134-135].

Теперь, для решения задач нашего исследования, подробно рассмотрим один из упомянутых видов параллелизма - синтаксический, или, как иначе его называют, синтаксически параллельные конструкции, и сделаем это на материале отобранных нами методом сплошной выборки примеров из произведений А.К. Дойла с целью доказать, что именно эти конструкции играют существенную роль при построении связного и цельного текста детективного жанра и оказывают непосредственное и важное влияние на восприятие текста его реципиентом.

Проанализировав работы отечественных авторов, раскрывающих суть синтаксического параллелизма (И.В. Арнольд, Н.В. Банина, Д.В. Беляев, И.А. Логвиненко, В.П.
Москвин, А.В. Николаева, В.Л. Страхова, Р.О. Якобсон), мы обнаружили, что подходы к определению и этого явления также различны.

В.П. Москвин относит этот вид параллелизма к синтаксическим повторам (грамматические формы/словосочетания/фразы) [5, с. 81-85]. И.В. Арнольд считает параллельные конструкции фигурами речи и называет их «синтаксически подобными конструкциями» ${ }^{11}$

Н.В. Банина также относит параллелизм к фигурам речи, но стилистическим ${ }^{12}$.

Согласно Н.В. Баниной, этот прием встречается в единицах больших, чем предложение и необходимым условием параллелизма является идентичность или схожесть синтаксических структур двух или более предложений (или частей предложений) при их последовательном употреблении ${ }^{13}$.

Параллелизм, как мы указывали выше, может быть, как полным, так и частичным (неполным).

Полный параллелизм - это повтор идентичных структур через соответствующие предложения ${ }^{14}$.

Рассмотрим на примерах из произведений А.К. Дойла, которые мы указали в начале нашей работы, как в тексте детективного жанра совместно и эффективно «работают» его когезия и когерентность, то есть, как при помощи синтаксического параллелизма автор достигает своей цели - нужного ему воздействия на понимание читателем его произведения (см. также [2], [3]).

\section{Примеры полного параллелизма:}

"In the dress is a pocket. In the pocket is a card-case. In the card-case is a note. And here is the very note ${ }^{m 5}$.

Здесь мы наблюдаем абсолютную идентичность конструкций в трех рядом стоящих простых предложениях. Использование таких конструкций - не случайно: один из героев (сыщик Скотланд-Ярда) рассказывает Ш. Холмсу поэтапность своего нахождения важной улики (записки) в совершении преступления. При прочтении предложений мы движемся вместе с героем от общего к частному: платье $\rightarrow$ карман $\rightarrow$

9 Ахманова О.С. Словарь лингвистических терминов. 5-е изд. М.: Либроком: URSS, 2009. С. 299.

10 Логвиненко И.А. Формальный параллелизм в поэтическом произведении (на основе стихотворений Б.Л. Пастернака) [Электронный ресурc]. URL: http://www.academia.edu/6519743/Формальный_параллелизм_в_поэтическом_произведении (дата обращения: 18.03.2021).

11 Арнольд И.В. Стилистика. Современный английский язык:Учебник для вузов. 4-е изд., испр. и доп. М.: Флинта: Наука, 2002. С. 104.

12 Банина Н.В., Мельничук М.В., Осипова В.М. Основы теории и практики стилистики английского языка. М.: Финансовый университет, 2017. С. 51.

13 Там же. С. 83.

14 Тамже. C. 84

15 Doyle A.C. The Adventures and Memoirs of Sherlock Holmes. Wordsworth Editions Limited, 2019. P. 214. 
футляр для визитных карточек $\rightarrow$ записка, что дает возможность читателю предвкушать что-то важное, которое вот-вот случится. В данном случае автор текста ведет реципиента своего произведения к правильному выводу о личности преступника.

В следующем примере - перед нами сложносочиненное предложение, состоящее из двух простых:

"It might be a lover; it might be a husband"16.

Мы также наблюдаем здесь полную схожесть конструкций в двух частях предложения, к тому же с использованием лексической анафоры, но вот далее имеет место антитеза: противопоставляются противоположные по смыслу слова (любовник и муж). Автор использует данные стилистические средства наряду с полным синтаксическим параллелизмом для того, чтобы дать описание мыслей детектива (Ш. Холмса), его рассуждений о личности одного из подозреваемых, тем самым заставляя читателя продумывать возможные комбинации хода событий (мотивация на дедукцию).

Нетрудно заметить, что в приведенных нами выше примерах полный синтаксический параллелизм встречается там, где предложения состоят из небольшого количества слов.

Частичный (неполный) параллелизм - это повторение некоторых частей предложений или частей придаточных предложений, следующих одно за другим ${ }^{17}$.

Рассмотрим теперь примеры частичного синтаксического параллелизма:

"He nearly fainted at the sudden shock of it; but he bit his lip and clenched his hands to hide his agony"18.

В данном предложении два раза повторяется модель глагол (в функции сказуемого в прошедшем времени) + местоимение (в функции определения) + существительное (в функции дополнения) с общим подлежащим (местоимение he) в рамках сложного предложения для перечисления тех действий, которые производил главный герой, чтобы справиться со своими эмоциями и не выдать себя, «заронить» зерно сомнения в поток сознания читателя, «отгадывающего» личность преступника.

В следующем предложении:

"All else in the man - his noble proportions, his fine features, and his frank bearing - fitted in with that jovial, man- to-man manner which he affected ${ }^{\prime \prime 9}$ представлена модель словосочетания, которая повторяется три раза в рамках одного предложения для описания внешности злодея, с использованием лексической анафоры (повтор местоимения his) для придания большей выразительности описанию с первого взгляда благородной, непричастной к преступлению личности, тем самым «сбивая читателя с правильного следа», слишком быстрого определения в тексте преступника.

В примере ниже наблюдается частичная синтаксическая схожесть предложений, находящихся на расстоянии друг от друга:

"Thank you, I am in no humor for a walk."

"Aren't you? The man's savage eyes were blazing with anger. Maybe you are in a humor for a fight, Mr Boarder!"20.

Конструкция в первом предложении частично повторяется во втором: но в первом случае присутствует отрицательная частица по, а во втором - наречие maybe и обращение Mr Boarder. При помощи синтаксического параллелизма и приема антитезы (walk - fight) автор создает напряженность в отношениях между двумя героями (сыщиком и преступником), которая в любую минуту грозит перерасти в драку, инициируемую преступником с целью снять с себя подозрения.

А.В. Николаева пишет о том, что в целом параллелизм больше характерен для английского языка, нежели для русского. Параллельные конструкции, сочетаясь со многими другими средствами выразительности (антитезой, инверсией, эллипсисом, рифмой, повтором, анафорой, эпифирой), придают тексту особую энергетику, динамику, усиливают его образно-языковое воздействие [6, с. 469]. Все это подходит и к текстам детективного жанра.

Рассмотрим еще ряд примеров:

"The house was an old-fashioned, widespread, oakbeamed brick building, with a fine lime-lined avenue leading up to $i t^{\prime 21}$.

Здесь синтаксически параллельные конструкции, выступая в роли определений, выраженных прилагательными, идут одна за другой, тем самым, создавая в сознании читателя, при их прочтении, четкую картину места (весьма непривлекательного), где будут разворачиваться странные и в итоге печальные события будущего преступления.

16 ibid. P. 222.

17 Банина Н.В., Мельничук М.В., Осипова В.М. Основы теории и практики стилистики английского языка. М.: Финансовый университет, 2017. С. 83.

18 Doyle A.C. The Hound of the Baskervilles \& The Valley of Fear. Wordsworth Editions Limited, 2011. P. 273.

19 Ibid. P. 261.

20 Ibid. P. 258.

21 Doyle A.C. The Adventures and Memoirs of Sherlock Holmes. Wordsworth Editions Limited, 2019. P. 340. 
Похожих примеров в рассматриваемых текстах детективного жанра достаточно много. Вот еще один из них:

"They all agreed that it was a huge creature, luminous, ghastly and spectral"22. Писатель прибегает к синтаксическому параллелизму (здесь представлен цепочкой прилагательных), чтобы навести ужас на читателя при описании собаки-убийцы и подтвердить его (реципиента) мысли о том, что такое существо способно совершать жуткие преступления, и поэтому не может быть исключено из подозреваемых.

\section{Рассмотрим еще пример:}

"It was just such a stick as the old-fashioned family practitioner used to carry - dignified, solid and reassuring ${ }^{\prime 23}$.

Здесь мы наблюдаем целую цепочку синтаксически параллельных конструкций, расположенных друг за другом в конце предложения. Делается это автором намеренно с целью обратить внимание на личность свидетеля, (в данном случае домашнего врача), который косвенно характеризуется через принадлежавшую ему вещь (все использованные в данном отрывке определения - прилагательные, и описывают одно и то же существительное - a stick - 'трость'), а качества последней (солидная, увесистая, надежная) одновременно характеризуют и самого владельца этой трости. При помощи синтаксического параллелизма у реципиента активизируются мыслительные процессы, формируется образ героя и его возможная значимость в раскрытии преступления.

Рассмотрим примеры, чтобы показать необходимость и «правильность» введения автором в текст синтаксически параллельных конструкций для решения им задач когерентного характера:

"We prospered, we travelled, we came back as rich colonials to England, and we bought country estates" ${ }^{\prime 24}$.

Здесь представлены четыре идентичные структуры в рамках одного предложения, построенные по модели местоимение (в функции подлежащего) + глагол (в прошедшем времени в функции сказуемого). Жизненные этапы преступников намеренно описываются автором произведения постепенно: разбогатели $\rightarrow$ начали путешествовать $\rightarrow$ вернулись $\rightarrow$ приобрели имения. Здесь также применяется лексическая анафора (начало с общего местоимения we). Подобная постепенность в повествовании создает отчасти некоторое напряжение, ожидание, предвкушение каких-то страшных событий (как затишье перед бурей).
"First he cleaned, oiled, and loaded his Smith \& Wesson revolver. Then he surveyed the room in which the detective was to be trapped $<\ldots$.. > Finally he discussed the matter with his fellow lodger"25.

Наличие синтаксического параллелизма здесь абсолютно очевидно: схожесть трех предложений заключается в использовании в них модели наречие (в функции обстоятельства времени) + местоимение (в функции подлежащего) + глагол (в прошедшем времени в функции сказуемого). Все три предложения начинаются с наречий, обозначающих этапы (последовательность) выполнения действий - sequence adverbs (перевод наш. - С.А.) first, then и finally. Синтаксический параллелизм в первом предложении используется автором, чтобы подчеркнуть реципиенту текста последовательность и тщательную спланированность выполнения всех действий героя при его подготовке к вполне очевидному применению им оружия во время поимки коварного преступника. Три сказуемых имеют при себе одно и то же дополнение revolver. При этом автор здесь же намеренно уводит мысли читателя от другого потенциального подозреваемого.

Далее, в представленном отрывке синтаксический параллелизм помогает связать все три предложения как грамматически (используется схожая схема построения начала предложения, описанная нами выше), так и по смыслу, поскольку во втором и третьем предложениях продолжается описание последовательности действий героя, осматривающего комнату, в которой он также тщательно готовит ловушку для преступника. То есть именно через синтаксический параллелизм в анализируемом тексте создается линия времени; выстраивается хронологическая композиция захватывающего сюжета. Поскольку в данном примере предложения находятся достаточно близко друг от друга (в рамках одного абзаца), автор создает тем самым напряженность ситуации, волнительное ожидание, подготавливает читателя к кульминации событий (злодей будет обязательно пойман), хотя на время развязка намеренно автором оттягивается. При помощи синтаксического параллелизма читатель произведения также понимает, что детектив особенно скрупулезно готовится к захвату, поскольку преступник матерый.

\section{В следующем примере:}

"We have books, we have our studies, and we have interesting neighbours"26, мы также наблюдаем три схожие структуры, построенные по модели местоимение (в функции подлежащего) + глагол (в настоящем времени

22 Doyle A.C. The Hound of the Baskervilles \& The Valley of Fear. Wordsworth Editions Limited, 2011. P. 24. Ibid. P. 5.

Doyle A.C. The Adventures and Memoirs of Sherlock Holmes. Wordsworth Editions Limited, 2019. P. 357. Doyle A.C. The Hound of the Baskervilles \& The Valley of Fear. Wordsworth Editions Limited, 2011. P. 313. Ibid. P. 73 
в функции сказуемого) + существительное (в функции дополнения), но с незначительными различиями в их лексическом и грамматическом составе. А именно - в первой конструкции отсутствует определение к дополнению books, в двух других (studies и neighbours) они есть (our и interesting), но относятся к разным частям речи.

В данном примере автор прибегает к синтаксическому параллелизму, который используется наряду с лексической анафорой we have (то есть, повтор одного и того же слова (выражения) в начале каждого самостоятельного предложения (в нашем случае в составе сложносочиненного), с целью отвлечь внимание читателя и отвести его подозрения от описываемых героев, ведущих размеренный образ жизни далеко от города, потому вряд ли способных совершить преступление.

При использовании синтаксического параллелизма важно, чтобы он «правильно» влился в общую структуру текста, что поможет формированию правильной (нужной автору) когерентности последнего на базе созданной в нем автором верной когезии, то есть текст не только структурно, но и грамматически должен быть верным, если синтаксически параллельные конструкции (слова и фразы в них) будут обязательно совпадать и по своей грамматической форме (например, по времени глагола), и по выполнению ими одной и той же функции в предложении (то есть быть, к примеру, дополнением к сказуемому).

Итак, синтаксический параллелизм - это не только элемент стиля. Идеи, мысли, информация, высказывания и т.д., объединяясь в единое целое (предложение, фразу, текст), начинают «жить» и «работать» в тесной гармоничной связи между собой. Согласно результатам проанализированного нами материала, мы пришли к выводу, что основным правилом построения синтаксических параллельных конструкций в текстах детективного жанра является то, чтобы элементы этой конструкции (к примеру, слова) были одной и той же частью речи (к примеру, глаголы), имели одинаковую грамматическую форму (например, все глаголы - в прошедшем времени), а также выполняли одинаковую функцию в предложении (например, определения к подлежащему).

В результате проведенного исследования было также установлено, что в текстах детективного жанра используется автором как полный, так и частичный синтаксический параллелизм, однако преобладает последний. На наш взгляд, это связано, прежде всего с тем, что с помощью неполного параллелизма автору более точно, последовательно, развернуто, а иногда и, наоборот, более завуалировано удается подавать читателю нужную, с точки зрения самого автора, информацию, что является важной характеристикой, а иногда и требованием именно к текстам детективного жанра. Скрупулезная последовательность писателя в этом случае может дать читателю ту необходимую для размышления и анализа ситуаций информацию «порционно», что повышает его мотивацию к дедукции, а следовательно, способствует развитию его когнитивного мышления. Проанализированные примеры, с нашей точки зрения, могут служить доказательством мысли о том, что, благодаря введению автором в текст детективного жанра синтаксически параллельных конструкций (как в пределы одного предложения, так и в несколько рядом стоящих предложений) возникает более последовательная (не только связанная со структурой текста) связь (когезия), но и связь на семантическом уровне, то есть происходит некоторое сближение фраз или целых предложений, что в результате приводит к более «комфортному», «заинтересованному» чтению реципиента, мотивирующему его к дедукции, и, в целом, к более успешному (в нужном для писателя русле) усвоению им всего текста произведения (когерентность). То есть синтаксический параллелизм выполняет текстообразующую функцию, поскольку в результате его использования текст становится более гармоничным: идеи автора передаются реципиенту четче, максимально исключая какую-либо двусмысленность при их восприятии (если только она не нужна автору детективного жанра намеренно).

Кроме того, синтаксически параллельные конструкции вместе с другими стилистическими средствами (например, анафорой) повышают выразительность самого текста и речь его героев, а следовательно, усиливают эмоциональность последней и производят на читателя нужный для писателя эффект.

Вообще, использование текстообразующей и экспрессивной функций синтаксически параллельных конструкций в произведениях детективного жанра, включая и произведения А. К. Дойла, чрезвычайно важно и оправдано, поскольку большое место в последних занимают эпизоды с описанием преступлений, хода расследования, личностей преступников (и других персонажей, задействованных в этих преступлениях), их диалогов, мыслей (дедукции) автора/детектива и прочее. Некорректность же или неточность в использовании автором произведения синтаксически параллельных конструкций могут привести к значительным сложностям при восприятии читателем текста детективного жанра, «повести его по ложному следу» (если только такой не был задуман автором намеренно), привести читателя к неправильным выводам, а следовательно, к некорректному, с точки зрения когезии и когерентности, сначала созданию автором произведения, а потом и к его прочтению, что приведет читателя к полной или частичной потери интереса к чтению произведения, к отсутствию мотивации к дальнейшему прочтению произведений этого автора, а, возможно, и к потере интереса к знакомству с произведениями детективного жанра в целом. 
Таким образом, роль синтаксически параллельных конструкций очевидна: они придают тексту нужный ритм: идеи и мысли плавно следуют одна за другой, делая посыл текста более убедительными, но главное - ис- пользование синтаксического параллелизма мотивирует реципиента к большему развитию когнитивности его мышления и делает процесс «расшифровки» текста автора полезным и интересным.

\section{ЛИТЕРАТУРА}

1. Гальперин И.Р. Текст как объект лингвистического исследования / Отв. ред. Г.В. Степанов. Изд. 10-е, стереотип. М.: ЛЕНАНД, 2019. 144 с.

2. Мазирка И.О. Вербальная характеристика личностных акцентуаций героев англоязычной художественной литературы // Вестник Московского государственного областного университета. Серия: Психологические науки. 2008. Т. 2. № 2. С. 8-18.

3. Мазирка И.0. Обоснование закономерностей исследования личности героя произведения в единстве философско-лингвистического, психолого-лингвистического, литературоведческого аспектов // Вестник Московского государственного областного университета. Серия: Философские науки. 2008. № 2. C. 13-20.

4. Макаров М.Л. Языковое общение в малой группе: опыт интерпретативного анализа дискурса: дис. ... докт. филол. наук. Тверь: Изд-во Тверс. гос. ун-та, 1998. 443 C.

5. Москвин В.П. Типология повторов как стилистической фигуры // Русский язык в школе. 2000. № 5. С. 81-85.

6. Николаева А.В. Параллельные конструкции в рекламных текстах (на материале английского и русского языков) // Доклады Башкирского университета. 2017. T. 2. № 3. С. 466-470.

7. Ришика К. Синтаксический параллелизм, его виды и функции в текстах русских народных сказок // Филологические науки. Вопросы теории и практики. 2017. № 2(68): В 2 ч. Ч. 2. С. 134-139.

8. Трофимова Э.А. Синтаксические конструкции английской разговорной речи. Ростов н/Д: Изд-во Рост. ун-та, 1981. 159 с.

9. Яшина Н.К. Лингвистика текста и перевод: монография / Владим. гос. ун-т им. А.Г. и Н Г. Столетовых. Владимир: Изд-во ВлГУ, 2013. 116 с.

10. Crossley S.A. \& McNamara D.S. Say more and be more coherent: How text elaboration and cohesion can increase writing quality // Journal of writing research. 2016. 7 (3). pp. 351-370. D0l: 10.17238/jowr-2016.07.03.02

11. Dontcheva-Navratilova 0., Jančaříková R., Miššíková G., Povolná R. Coherence and Cohesion in English Discourse. Brno: Masaryk University, 2017. 158 p. D0I: 10.5817/CZ.MUNI.M210-8857-2017

12. Halliday M.A.K., Hasan R. Cohesion in English. London: Longman, 1976. 392 p.

13. Karadeniz A. Cohesion and Coherence in Written Texts of Students of Faculty of Education // Journal of Education and Training Studies. 2017. vol. 5. no. 2. pp. 93-99. D01:10.11114/jets.v5i2.1998

( С Соколова Алевтина Владимировна (alevtina-sokolova@rambler.ru). Журнал «Современная наука: актуальные проблемы теории и практики» 